\title{
A system dynamics approach to risks description in megaprojects development
}

Prince Boateng

Institute for Building and Urban Design, School of the Built EnvironmentHeriot-Watt University, Edinburgh-UK haggboat@yahoo.com
Zhen Chen

Institute for Building and Urban Design, School of the Built EnvironmentHeriot-Watt University, Edinburgh-UK

Zhen.Chen@hw.ac.uk
Stephen Ogunlana

Institute for Building and Urban Design, School of the Built EnvironmentHeriot-Watt University, Edinburgh-UK

S.O.Ogunlana@hw.ac.uk
Dubem Ikediashi

Institute for Building and Urban Design, School of the Built EnvironmentHeriot-Watt University, Edinburgh-UK

isaacikediashi@yahoo.com
DOI 10.5592/otmcj.2012.3.3 Technical and research paper

\section{Keywords}

Megaproject, Risks, System dynamics, Tram project
THE INHERENT RISKS AND THEIR INTERACTIVE IMPACTS IN MEGAPROJECT DEVELOPMENT HAVE BEEN FOUND IN NUMEROUS CASES ACROSS THE WORLD. Although risk management standards have been recommended for the best practice, there is still a lack of systematic approaches to describing the interaction among social, technical, economic, environmental and political (STEEP) risks with regard to all complex and dynamic conditions of megaproject construction for better understanding and effective management of the management mechanism in terms of the nature risks, including their dynamic interactions and impacts in megaproject development. Purpose - Present a model to describe STEEP risks and their interactions in megaproject development.

Design/methodology/approach - A case study methodology is adopted. Following comprehensive literature review, qualitative data were gathered from case studies through interview conducted on Tram Network Project in Edinburgh. Casual loops of typical evolution of key indicators of risks were then developed and a hypothesised model of social and environmental (SE) risks was derived using system dynamics (SD) modelling technique. The model was then set up in accordance with British Standards on risk management in order to provide a generic tool for risk management in megaproject development.

Findings - The study reveals that cost and time overruns at the developmental stage of the case project are caused mainly by the ineffectiveness of traditional risks assessment techniques used in assessing risks on timely basis and accurate information from the early stages of the project. Evidences collected are used to explain the nature of STEEP risks in particular, the SE risks in the past stages of project development. Further research is also discussed for applying SD methodology in risk management in megaproject development. 


\section{INTRODUCTION}

Risks in megaprojects construction are usually complex and uncertain. They are often referred to as the presence of potential or actual treats or opportunities that influence the objectives of a project during construction, commissioning, or at time of use (Gray, 2006). Despite the coming of age of risk management as a profession, Baker et al., (1998) established that "there is no global (project risk management) industrial standard" or procedures that exist for what constitutes a risk assessment. This implies that, there is wide range of risk management standards been discussed in literature and within the domain of project management. Some of these standards include the BS 31100:2008; BS ISO 31000:2009; BS EN 31010:2010; BS 6079-3:2000 and BS IEC 62198:2001 and the risk management standards published jointly by the Association of Insurance and Risk Managers (AIRMIC), the National Forum of Risk Management in the Public Sector (ALARM), the (AIRMIC et al, 2002) and CIRIA guide to the systematic risk management for construction (Godfrey, 1996). However, these risks management standards put forward to guide for the best practice for such a complex system like megaproject construction have not been critical enough in managing or mitigating risks from the external project environment. The conventional Standards still lack systematic approaches to describe all the interactions among the social, technical, economic, environmental and political (STEEP) risks with regard to all complex and dynamic conditions through megaproject construction that can be disastrous and can cause chronic project failure during construction.

\section{Aim and objectives}

Based on the above consideration, this paper uses System Dynamics (SD) modelling for social and environmental (SE) risk management during megaprojects development. This will be achieved through the following objectives:
Develop SD risk assessment model to support the over 30 risk assessment techniques in the British Standards of risk management: BS 31100:2008; BS ISO 31000:2009; and BS EN 31010:2010.

Demonstrate the effectiveness of the new SD model using an experimental case study

The significant contribution of this paper include a set of risk assessment tools for macro external project risks and an SD model designed for SE risks impact on megaproject development. It is expected that the constructed SD models will serve as promising strategic decision tools to megaproject developers for experiment during policies making and to implementing them to real situations.

\section{Literature review}

The literature review focuses on the two main areas of endeavour: (a) STEEP Risks in megaproject development (b) cost and time overruns in megaprojects construction. These two areas are selected because of their documented history in impacting upon mega construction and engineering projects:

\section{STEEP risks in megaproject}

development

Risks in developmental phases of megaprojects take place within a complex web of numerous social, technological, economic, environmental and political (STEEP) environments of all types in global dimensions (Chen et al., 2009 and 2011). As a result, such large projects become: (1) extremely complex, consisting of multiple interdependent components, (2) highly dynamic, (3) involve multiple feedback process, (4) have nonlinear relationships and (5) require both "hard" and "soft" data (Sterman, 1992). Brief definitions of each of the STEEP risks are as follows:

Social Risks: These include national and local-level factors that contribute to social (in) stability (such as levels of governance, security and population size) as well as project specific issues (the nature of the project approval process, the outcomes of similar projects previously conducted in the area, bad sub-contractor qualification, communication and low labour productivity, inexperience project manager, confusion of personnel management etc.)

- Technological risks: These risks are mainly treats that prevent the operations of the contracting companies to develop, deliver, and/or manage its services, and to support operations.

- Economic risks: Risks to constructing the Tramline projects as a result of the adjustments of national economic policy, inflation, fluctuate of price, interest rate and exchange rate due to the relative long period of delivery of such projects.

- Environmental risks: These are natural risks such as unfavourable climatic conditions (continuous rainfall, snow, temperature, wind), force majeure (thunder and lightning, earthquake, flood, hurricane, etc.) that have tremendous influence on the project and the bad environmental conditions (pollution, traffic, etc.) of construction activities on the physical environment.

> Political risks: Tram network projects, mostly belonging to a state (country) or the government, are easily influenced by the adjustment of state laws, regulations, and government policy.

Together, these STEEP risks (Figure 1) interact with one another to influence relationships and to generate risk landscapes of unprecedented complexities.

A further increase of such interactions with one another can produce system disturbances with severe consequences and would in turn generate collateral effects via spreading and cascading failures within project interrelated subsystems (Boateng et al., 2012). The results will then be crippling losses of public invested funds and valuable time that were previously thought to be uncorrelated and unforeseeable (Kytle and Ruggie, 2005). 


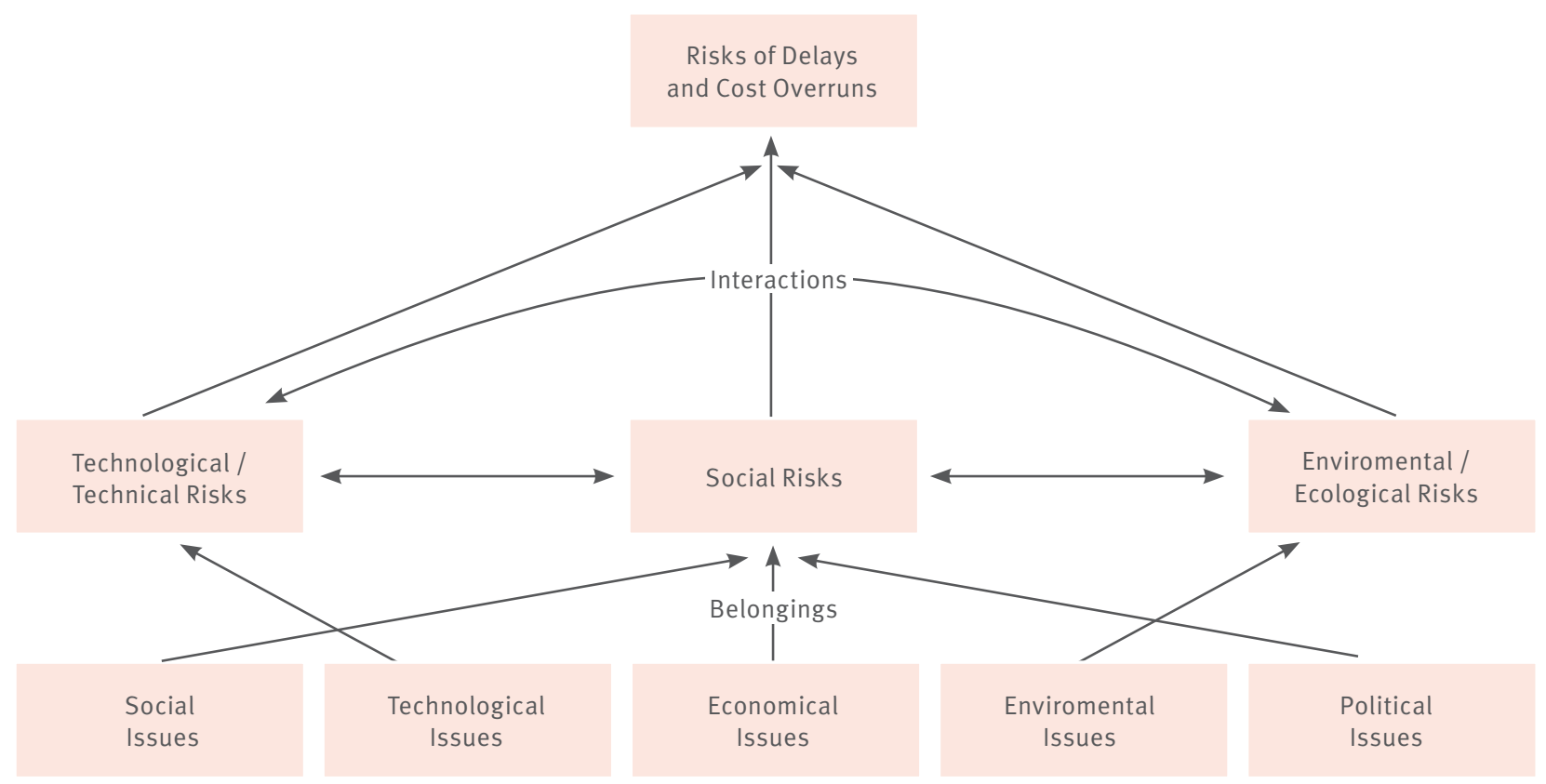

Figure 1 The effects of Interactions and belongingness of STEEP factors in megaproject dev.

Cost and time overruns in megaprojects construction

Evidence suggests that such megaprojects are usually money pits where funds are swallowed up without delivering sufficient returns. This is due to unbalanced subjective beliefs and information in assessing risks and uncertainties, and taking corrective actions to control and manage the identified risks. For example, in Poole (2004), the transportation infrastructure industry has been revealed to have a major credibility problem. It has a bad track record on megaproject development. The project costs are often grossly underestimated, and traffic, often overestimated. These problems are well documented in literature for many recent rail projects across the globe.

A study was carried out by Danish academic Bent Flyvbjerg and colleagues on 258 highway and rail projects (USD9o billion worth) in 20 countries in a book called Megaprojects and Risk (Cambridge University Press, 2003). The study revealed that transportation infrastructure projects do not perform according to budgets as estimated. According to the study, the vast majority (90\%) suffered cost over- runs, with the average rail project costing $45 \%$ more than projected, and the average highway project $20 \%$ more. Traffic forecasts were also far from accurate, with rail projects generating an average of $39 \%$ less traffic than forecasted (though highway projects averaged a $9 \%$ underestimate of traffic). Based on a continuous research, Bent Flyvbjerg emphasized that cost overrun has not decreased over the past 70 years and furthermore seems to be a global phenomenon.

Further high profile highway projects, are Boston's Central Artery/Tunnel, the "Big Dig" and Virginia's Springfield Interchange. These projects have made practitioners in the construction industry, and public taxpayers acutely aware of the problems of project delay and cost overruns. For example, the Big Dig was estimated at a cost of US\$ 2.6 billion but was completed at a cost of US\$ 14.6 billion. Additionally completion was delayed from 2002 to 2005 . This indicates that construction cost estimating on major infrastructure projects has not increased in accuracy over the past 70 years. The underestimation of cost today is in the same order of magnitude that it was then (Flyvbjerg, 2006b, 2007). According to Flyvbjerg et al. (2003), there is need for new ideas and techniques to be developed to improve this area where no leaning seems to have taken place. Flyvbjerg however proposes reference class forecasting approach to cope with complex problems in megaprojects through the following three steps:

1. Identify a reference class for past but similar projects.

2. Establish a probability distribution for the selected reference class parameter to be forecasted.

3. Compare the specific project with the reference class distribution in order to establish the most likely outcome for the specific project.

As a result of the aim and objectives of this paper and concerns raised by the literature review, the following section presents methodologies used for modelling and assessing SE risks for similar megaproject cases.

\section{Research Methodology}

The methodologies adopted in this research are case studies, SD modelling and interview with experts involved in megaprojects. 


\section{Case study}

To understand the subject of this research, systematic gathering of empirical data on Edinburgh Tram Network Project (ETNP) was carried out. The reason was to ensure unbiased judgement during analysis and for validation purposes. The choice of ETNP was based on the fact that, its development has been faced with numerous challenges relating to cost, time and specification and therefore has encountered cost and time overruns. The results obtained were initially used to describe and justify the SD methodologies adopted for this research, and furthermore provided descriptive features beyond studying surround context. The method further elaborated on detailed findings, and made accurate observation and rigorous collection of evidence on the SE risks impacts on the case project.
At the time of data collection, the project had been under development for four years and suffered time delays, cost overruns and other risks such as contractual disputes and utilities diversion problems. From the interview conducted, it was revealed that the project was improperly forecasted than initially expected and as a result, must face cost and time overruns. After long legal battles between the developer and the owner, the project has now been rescheduled to be completed in 2014 , three years ahead of the original completion date in 2011 from line two to line one. When completed, it will be one of the most modern tram network projects in the world. Table 1 provides a summary of the initial basic information of the project.

Data collected were from project documents, online published Audit reports

\begin{tabular}{|c|c|}
\hline Project Title & Edinburgh tram network project \\
\hline Purpose & $\begin{array}{l}\text { - To support the local economy by improving accessibility. } \\
\text { - To promote sustainability and reduce environmental } \\
\text { damage caused by traffic. } \\
\text { - To reduce traffic congestion. } \\
\text { - To make the transport system safer and more secure. } \\
\text { - To promote social benefits. }\end{array}$ \\
\hline Scope & $\begin{array}{l}\text { - To connect Edinburgh Airport to the City Centre } \\
\text { - To link with development areas in North and West } \\
\text { Edinburgh }\end{array}$ \\
\hline Contractual Framework & $\begin{array}{l}\text { - Development Partnering and Operating Franchise } \\
\text { - Sgreement (DPOFA); } \\
\text { - Joint Revenue Committee (JRC); } \\
\text { - Multi Utilities Diversion Framework Agreement (MUDFA); } \\
\text { - Infrastructure provider and maintenance (Infraco); and } \\
\text { - Vehicle supply and maintenance (Tramco). }\end{array}$ \\
\hline $\begin{array}{l}\text { Relevant physical } \\
\text { dimension }\end{array}$ & $\begin{array}{l}\text { - Total length: } 24 \mathrm{~km} \text { in two phases } \\
\text { - Phase } 1 \mathrm{a}: 18.5 \mathrm{~km} \text {, is underdevelopment (Case study) } \\
\text { - Phase } 1 \mathrm{~b}: 5.5 \mathrm{~km} \text {, to be developed later }\end{array}$ \\
\hline Cost ( $f$ million) & $\begin{array}{l}\text { - Planned project budget } 545 \\
\text { - Validated budget } 776 \\
\text { - Cost variation } 231\end{array}$ \\
\hline Year of completion & $\begin{array}{l}\text { - Original planned date } 2011 \\
\text { - Expected new date } 2014\end{array}$ \\
\hline
\end{tabular}

Table 1 Basic information of Edinburgh tram network project, Source: Edinburgh Tram Project, the City of Edinburgh Council reportno. CEC/41/11-12/CE

of the City Council, structured interviews and technical summaries. Information sought were basic project information, STEEP problems encountered and actual project performance relating to time, cost and specification achieved to date. Local business owners, operators, customers and project managers were interviewed in order to gain insight into STEEP problems relating to the project, verify the model structures and to obtain soft data that could not be obtained from project documents and published reports. The results were used to explain why delays and cost overruns occur in megaproject development by determining causes and effects through feedback loop diagrams.

\section{The systems dynamics}

The systems dynamics (SD) methodology is adopted in this study. The SD methodology is a field created at MIT by computer pioneer Jay Forrester in mid 1950 o for modeling and analyzing the behavior of complex social systems in an industrial context (Sterman, 2000). It was designed to help decision-makers learn about the structure and dynamics of complex systems, to design high leverage policies for sustained improvement, and to catalyze successful implementation and change. In recent years, the SD has been used by researchers and project managers to understand various social, economic and environmental systems in a holistic view (Rodrigues 1996; Towell 1993; Sycamore 1999; Mawby 2002; Love 2002; Ogunlana 2003 and Naseena 2006).

The system dynamics approach is primarily based on cause-effect relationship. This cause-effect relationship is explained with the help of stock, flow and feedback loops. Stocks and flows are used to model the flow of work and resources through the project. Feedback loops are used to model decisions and project management policies. System Dynamics can be used to model processes with two major characteristics: (1) those involving change over time, and (2) those involving feedback (Ogunlana 2003). 


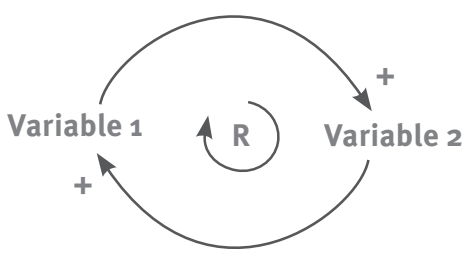

2a. A Reinforcing Loop

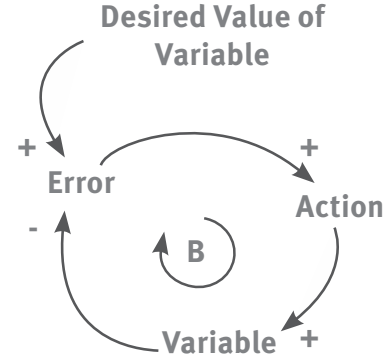

2b. A Balancing Loop

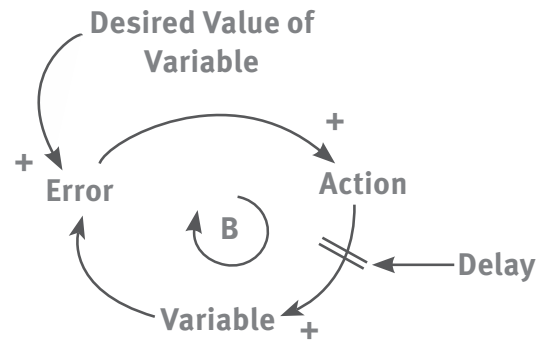

2c. A Balancing Loop with Delay

' $\longrightarrow$.. A cesual relathionship

$+(-) \quad$ Signs at the arrowheads indicate the effect is positively (negatively) related to the cause

// Sign on the arrow indicates material and / or information delay $\mathrm{R}$ denotes Reinforcing loop and $\mathrm{B}$, the Balancing loop

Figure 2 The three components of system dynamics models

The central concept of System Dynamics is to understand how the parts in a system interact with one another and how a change in one variable affects the other variable over time (Senge, 1990), which in turn affects the original variable (See Figure 2). Systems can be modeled in a qualitative and quantitative manner. The models are constructed from three basic building blocks: positive feedback or reinforcing loops, negative feedback or balancing loops, and delays. Positive loops (reinforcing loops) are self-reinforcing while negative loops (balancing loops) tend to counteract change. Delays introduce potential instability into the system.

Figure 2 a shows a reinforcing loop, which is a structure that feeds on itself to produce growth or decline. Reinforcing loops correspond to positive feedback loops in control theory. An increase in variable 1 leads to an increase in variable 2 (as indicated by the "+" sign) and that leads to an additional increase in variable 1 and so on. The "+" sign does not mean the values necessarily increase, only that variable 1 and variable 2 will change in the same direction (polarity). If variable 1 decreases, then variable 2 will decrease. In the absence of external influences, both variable 1 and variable 2 will clearly grow or decline exponentially.
Reinforcing loops generate growth, amplify deviations, and reinforce change.

A balancing loop (Figure $2 \mathrm{~b}$ ) is a structure that changes the current value of a system variable or a desired or reference variable through some action. It corresponds to a negative feedback loop in control theory. A (-) sign indicates

\begin{tabular}{|c|c|c|}
\hline Researchers & Year & Summary \\
\hline De-Marco, A. \& Rafele, C. & 2009 & $\begin{array}{l}\text { A feedback process to understand } \\
\text { construction project performance }\end{array}$ \\
\hline $\begin{array}{l}\text { Nasirzadeh, Afshar and } \\
\text { Khanzadi }\end{array}$ & 2008 & An approach for construction risk analysis \\
\hline Mugeni-Balyejusa, B. & 2006 & Modelling changes in construction projects. \\
\hline
\end{tabular}

Howick, S.

2003

Ogunlana, Sukhera and Li 2003

Love, Holt, Shen, Li and Irani 2002

Park, M. 2002 Change management for fast-tracking construction projects

Chritamara. S and Ogunlana. S.

2002

Modelling of design and build construction projects
Disruption and delay in complex projects for litigation
Performance enhancement in a construction organization.
The need for understanding of how particular dynamics can hinder the performance of a project management system.

\begin{tabular}{|c|c|c|}
\hline Park, M. & 2002 & $\begin{array}{l}\text { Change management for fast-tracking } \\
\text { construction projects }\end{array}$ \\
\hline $\begin{array}{c}\text { Chritamara. S and Ogunlana. } \\
\text { S. }\end{array}$ & 2002 & $\begin{array}{l}\text { Modelling of design and build construction } \\
\text { projects }\end{array}$ \\
\hline Rodrigues, A. and Bowers, J. & 1996 & $\begin{array}{l}\text { A comparative analysis between two } \\
\text { approaches to project management. }\end{array}$ \\
\hline
\end{tabular}

Table 2 Applications of system dynamics in research into construction project management, Source: Boateng et al., 2012 
that the values of the variables change in opposite directions. The difference between the current value and the desired value is perceived as an error. An action proportional to the error is taken to decrease the error so that, over time, the current value approaches the desired value. The third basic element is a delay; this is used to model the time that elapses between cause and effect and is indicated by a double line (Figure 2c). Delays make it difficult to link cause and effect (dynamic complexity) and may result in unstable system behaviour.

In Systems Dynamics, verbal descriptions and causal loop diagrams are more qualitative; stock and flow diagrams and model equations are more quantitative ways to describe a dynamic situation. As systems Dynamics is largely based on the soft systems thinking, (learning paradigm), it is well suited to be applied on those managerial problems which are ambiguous and require better conceptualization and insight (Sushil 1993) than what the conventional methods such as PERT/CPM techniques can provide. As indicated in table 2, the SD has been successfully used in construction project related research (Nasirzadeh et al., 2008).

Unlike the conventional approach (PERT/CPM), where planners use human judgement to interpret their own mental models, the SD approach according to Sterman (1992), uses computer models to overcome limitations of the mental models. Sterman established that, the SD computer models are explicit and open to all to review; capable to compute the logical consequences of the modeller's assumptions; able to interrelate many factors simultaneously and finally, can be simulated under controlled conditions for analysts to conduct experiments outside the real system. Table 3 indicates some of the capability differences between the two approaches which make SD a preferred choice over the PERT/CPM in megaproject planning against SE risks.

\begin{tabular}{|c|c|c|}
\hline Capability & PERT/CPM & System dynamic \\
\hline Capturing managerial corrective actions & Low & Very high \\
\hline Realistic actions for project acceleration & Low & Very high \\
\hline Detailing level & High & Very high \\
\hline Risks and uncertainty management & High & Very high \\
\hline Evaluating impact of uncertainties & High & Very high \\
\hline Evaluating decision level & High & Very high \\
\hline $\begin{array}{l}\text { Estimating accurate project cost, duration \& } \\
\text { resources }\end{array}$ & High & Very high \\
\hline Work schedule & High & Very high \\
\hline Project control and monitoring & Yes & Yes \\
\hline Showing interrelationship & Yes & Yes \\
\hline Accounting for feedback effects & Yes & Yes \\
\hline Work specification & Yes & No \\
\hline Assigning responsibilities & Yes & No \\
\hline Handling multi interdependent components & No & Yes \\
\hline Productivity impact consideration & No & Yes \\
\hline Handling multiple feedback processes & No & Yes \\
\hline Handling non-linear process relationship & No & Yes \\
\hline Computational capability for predictions & No & Yes \\
\hline
\end{tabular}

Table 3 Capability differences between PERT/CPM and the System dynamics tools / Based on desktop study

\section{Discussions}

The model structure

The model is divided into five subsystems as Social, Technological, Economical; Environmental and Political (Figure 3). Each of these sub-systems consists of numerous variables and equations. Due to space limitation, the social and environmental (SE) subsystems are only considered in this study. The model boundary chart (Table 2) indicates detailed results of the variables under each of the two subsystems considered.
The model boundary chart

The model is bounded in the construction phase and for the developer. The boundary chart (see Table 4) is a chart which summarizes the scope of a model by categorizing the variables of identified SE risks into endogenous and exogenous.

Endogenous variables are those represented within the model with values determined or influenced by one or more of the independent variables in the system. Exogenous variable on other hand, are factors which are outside of the model of each subsystem. Although, 


\begin{tabular}{|c|c|c|}
\hline \multirow{2}{*}{ Model subsystem } & \multicolumn{2}{|c|}{ Model variables } \\
\hline & Endogenous & Exogenous \\
\hline Social & $\begin{array}{l}\text { - Multi-player/level } \\
\text { decision making } \\
\text { - Social issues } \\
\text { - Social acceptability } \\
\text { - Social grievances } \\
\text { - Legal action } \\
\text { - Reputational risks }\end{array}$ & $\begin{array}{l}\text { - Construction disruptions } \\
\text { - Need to relocate } \\
\text { - Pedestrian and bicycle safety } \\
\text { - Accessibility to families, friends and } \\
\text { community resources } \\
\text { - Choice of travel modes } \\
\text { - Linkage between residence and job } \\
\text { - Land and property value } \\
\text { - Waste generation } \\
\text { - Pollution (water, air etc...) } \\
\text { - Dust } \\
\text { - Transport issues (traffic) } \\
\text { - Stakeholders satisfaction } \\
\text { - Regulatory environment }\end{array}$ \\
\hline Environmental & $\begin{array}{l}\text { - Climate change } \\
\text { - Construction disruption } \\
\text { - Adverse environmental } \\
\text { impacts }\end{array}$ & $\begin{array}{l}\text { - Adverse climatic conditions } \\
\text { - Ecological/social issues }\end{array}$ \\
\hline
\end{tabular}

Table 4 SE Model boundary chart

such variables have impacts on the outcome of the model, changes in the model do not affect them. The variables include those for the SE risk factors which impact on ETNP during construction.

\section{Model construction}

A typical system dynamics model goes through some standard steps. Although there will be variations depending on the nature of the problem and style of the modeller. The main steps for modelling in this study can be summarized (see Figure 4) as follows:
Problem identification and definition

1. Initial model development

2. Model verification (expert opinion)

3. Final model development

4. Model simulation (Analysis of model behaviour)

5. Model validation using software tools and case studies

6. Policy analysis, model use or implementation

Based on the results in table 4 , the cause and effect diagrams in figure 5 were modelled with SD methodological

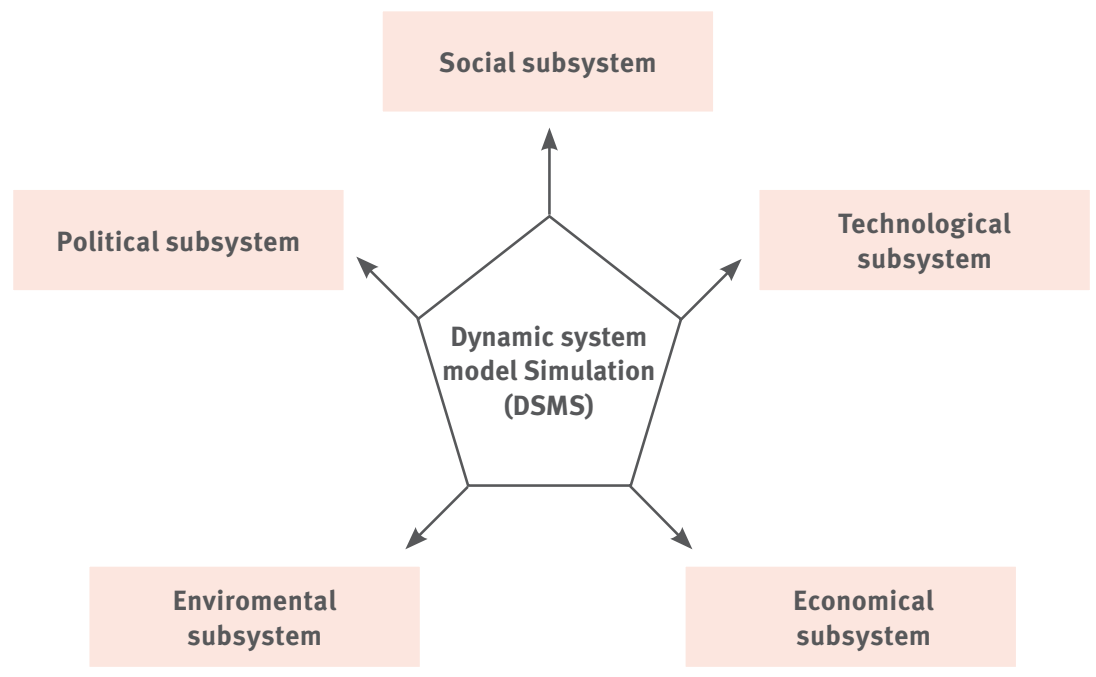




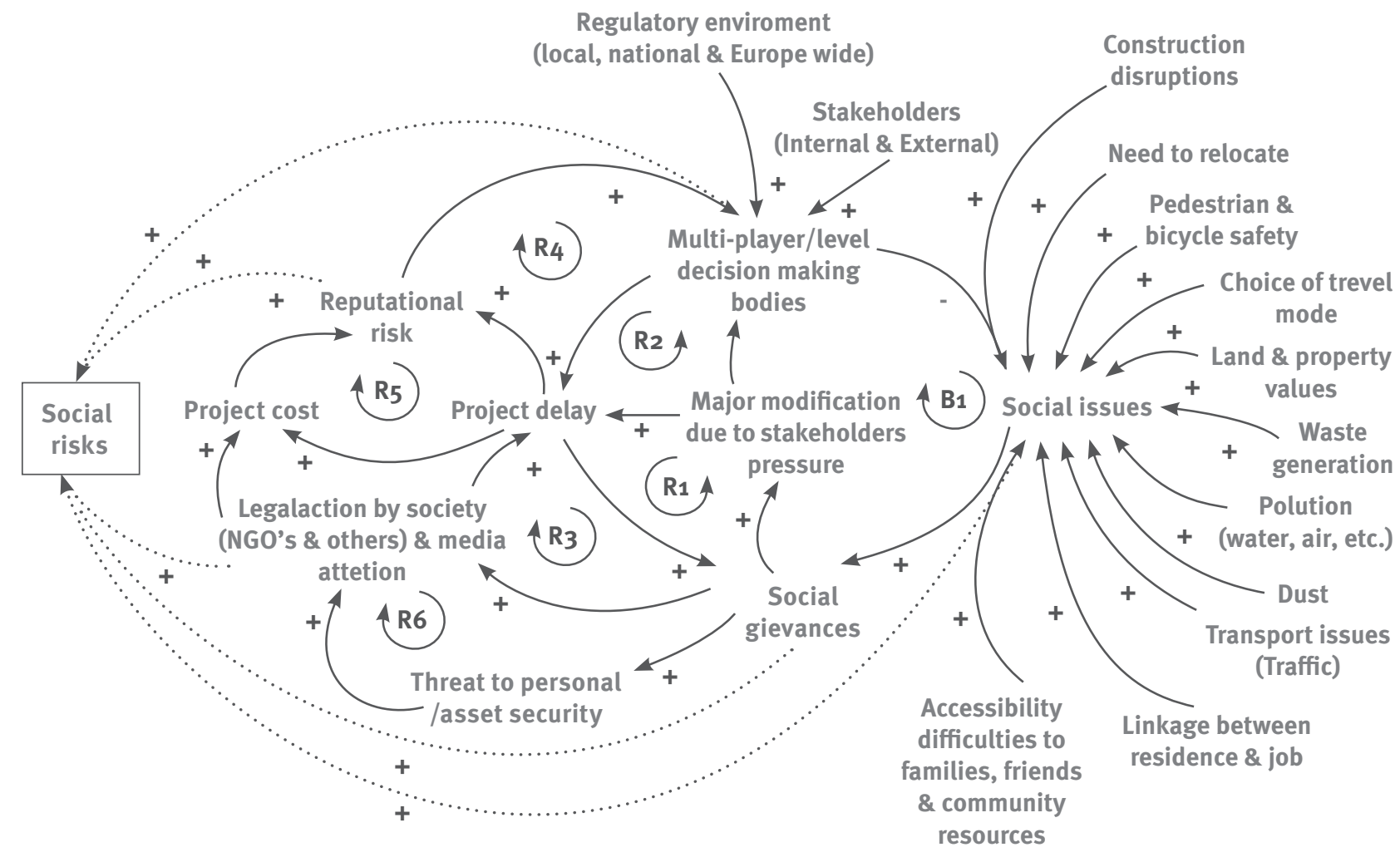

b. Cause and effects feedback loop for the environmental/ecological subsyste

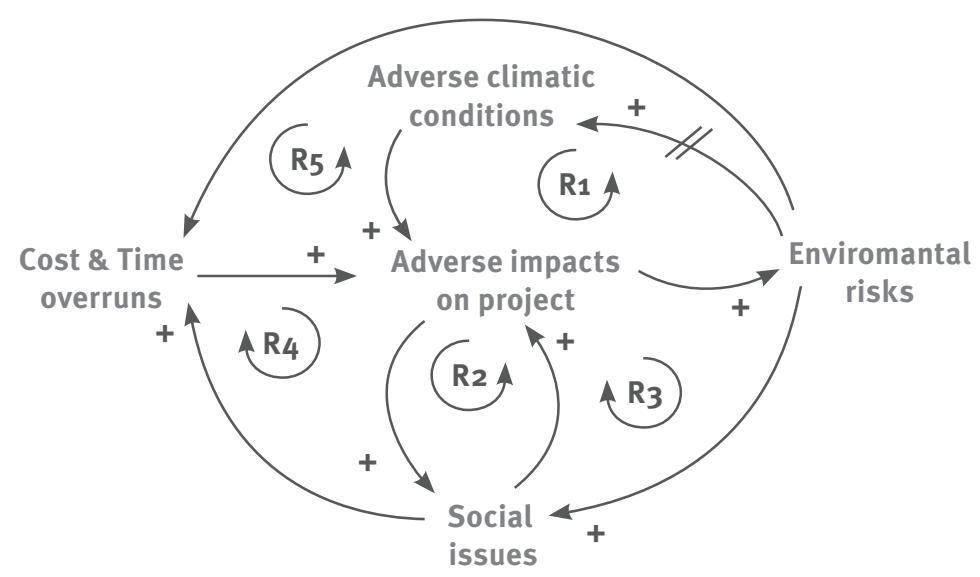

Figure 5 Feedback structures for social and environmental subsystems

development. On the other hand, figure $5 \mathrm{~b}$ indicated adverse impacts on the project from climatic conditions and social issues. These impacts, however, led to environmental risks, a further impact on the social environment through to project cost and time overruns. The arrows indicate cause-effect relationship and have a plus (+) sign when the cause increases the effects while the minus (-) sign indicating a decrease of the effect from the cause. There are two feedback loops ( $R$ and $B$ ) in Figure 5. The loop R1 denotes a reinforcing loop or positive loop and shows increase in the system from the social grievances through major modification due to stakeholders' pressure to project delay thereby caus- ing reinforcement within the system. The other loops with B signs indicate balancing or negative loop. In loop B1 for example, increased in multi-player/ level decision making bodies will decrease social issues and social grievances. The practice will further reduce frequent modification to project scope due to stakeholders' pressure to project 


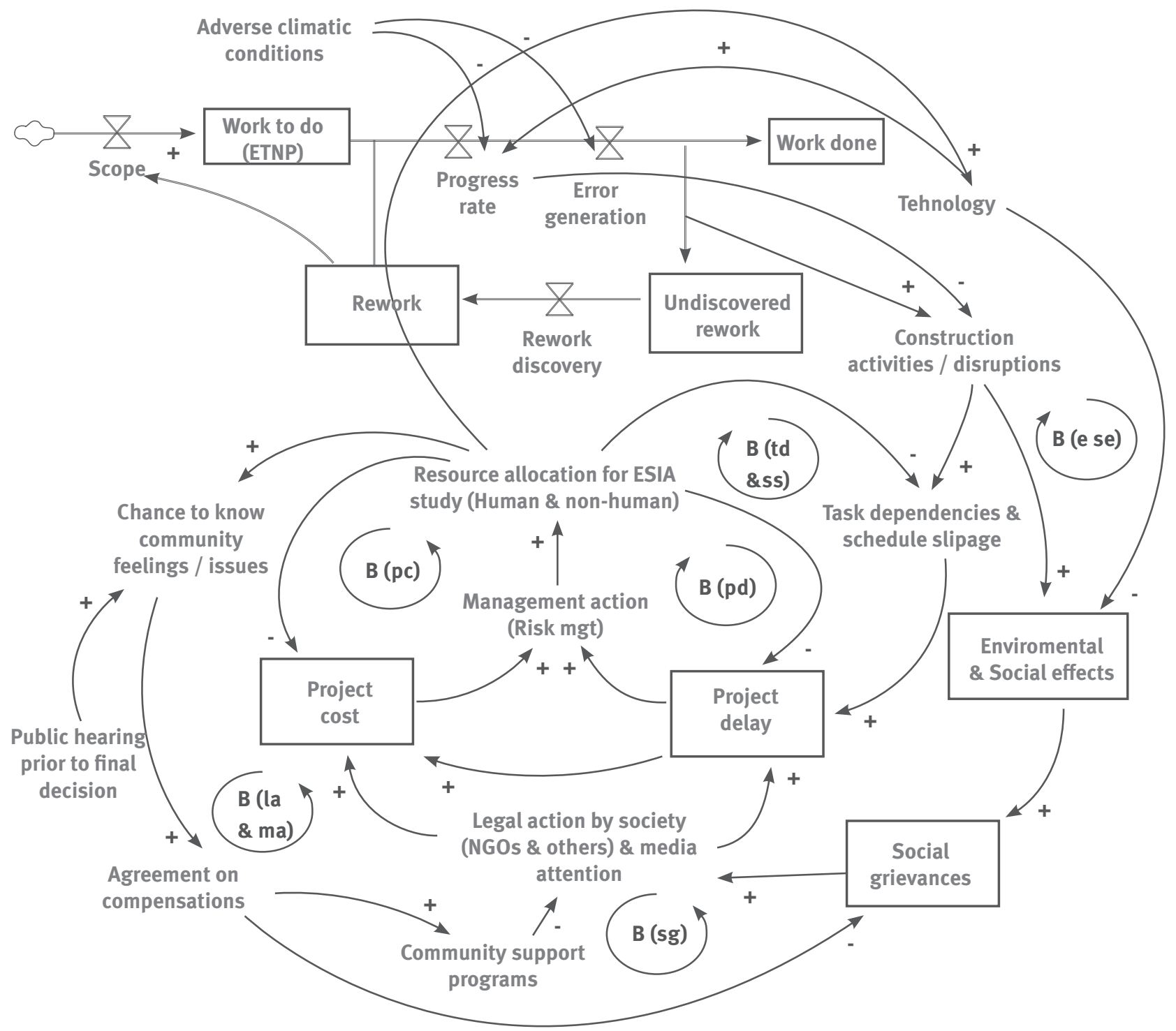

: A casual relationship

+ (-) signs at the arrowheads indicate that the effect is positively (negatively) related to the cause.

B denotes balancing loop.

$\triangle$ : Valve of flow

$\leadsto$ : Rate or flow

: Accumulation of Tasks, project cost, project delay, social grievances and SE effects

Figure 6 Dynamic hypothesis demonstrating social and environmental risk management in megaproject construction

on track. Complexities will occur when divergence views of regulatory bodies and stakeholders are not dynamically correlated, thereby causing chaotic time and cost overruns.

Dynamic hypothesis

Both qualitative and quantitative results which lead to SE risks in the case project were used to construct the final feedback model to address the systematic issues of time and cost overruns in megaproject construction. The SD models were set up in accordance with British Standards on risk management in order to provide a generic tool for risk management in megaproject development in five steps: risk management planning, risk identifi- cation, qualitative and quantitative risk analysis, risk response planning, risk monitoring and control.

Step1.- Risk management planning Within the SE risk management planning, Figure 5 and 6 allow for feedback loops concerning project delay and project cost overruns. These figures provide define structure levels of risk manage- 
ment within the activities of project risk planning and can be use by planners to pro-actively test and improve the existing project plan such as forecasting and diagnosing the likely outcomes of the current plan.

> Step2. - Risk identification

The SD models can support risk identification in a qualitative level through the influence diagrams. Given SE as specific risks, it is possible to identify which feedback loops favour or counter the occurrences of such risks. In loop B (la \& ma) (see Figure 6), the public participation in the Environmental and Social Impact Analysis (ESIA) drives public feelings and their feedback on the direct or indirect impacts of the project magnitude to be understood. This can help the Project management team to formulate and agree on what compensatory packages to be given out to the affected community by the tram construction. The identification of the project affected group and effective community support programs will also minimise legal actions by the society and thereby creates good relationship within the project environment.

Step3. - Risk analysis

The influences shown in the models can further assist project managers of the tram network project to assess SE risks in both qualitative and quantitative manners. In the qualitative analysis, each feedback loop can be a dynamic force that pushes away from the risk occurrence. With regards to risk likelihood, magnitude and impacts, a simulation model can best be used to identify and capture full impacts of potential SE risks on the project. Further impacts of risks can be quantified and simulated to generate a wide range of estimates and scenarios to reflect the full impacts of the SE risks occurrences and impacts on Trams Network Project during construction.

> Step4. - Risk response planning The models can be effectively used to support risk response planning in Tramline projects and other similar megaproject development in three ways.
Provide feedback perspective for SE risks identification.

Provide a better understanding of the multiple- factor causes of risks and a trace through the chain to identify further causes and effects.

Serve as powerful tools to support project managers to devise effective responses.

Step5. - Risk monitoring and control The models provide effective tools for risk monitoring and control. Through the cause and effects diagrams, early signs of unperceived risks emergences can be identified to avoid aggravation. In addition, simulated models can provide effective monitoring and control mechanism for risks diagnosis.

\section{Conclusions}

With the assistance of a practical survey, this paper has systematically examined major SE risks affecting the megaproject construction using Edinburgh Trams Network Project as a case study. The risk models developed in this paper, supported by examining real risk cases, provides an effective insight and clear picture of the SE risks involved in megaproject development and construction. The understanding of these SE risks is essential in order for planners to take proper risk management strategies.

The investigation of several practical risk management strategies demonstrates effective examples of adopting risk management principles to provide useful references to megaproject planners and developers or those overseas firms who are planning to operate their businesses in the UK. The findings and analysis in this paper would present valuable data for the initiating Government and local partners to have an indepth understanding of the SE risk environment to the construction of megaprojects. Such understanding is vital for implementing further effective measures to ensure that the right direction of future development create a more attractive environment to all stakeholders to avoid project delay and cost overruns.

\section{Future Research}

To enhance the performance of the existing risk management processes, future research on Social, Technology, Economic, Ecology and Political (STEEP) risks in construction and engineering projects will be modelled using system dynamics methodology to aid multicriteria decision making during risk management. The future research will also look into STEEP risks from more megaprojects to support the building of decision making to improve the understanding and accuracy of the management of megaprojects using system dynamic models.

\section{References}

AIRMIC, ALARM and IRM (2002), “Risk
Management Standard” Available at: http
www.theirm.org/publications/documents
Risk_Management_Standard_030820.
(accessed 21 March 2012)
Baker, S., Ponniah, D. and Smith, S (1998)
Techniques for the Analysis of Risks in
Major Projects., Journal of Operational
Research Society, 49, 567-572.

Boateng, P., Chen, Z and Ogunlana, S.O. (2012) A conceptual system dynamic model to describe the impacts of critical weather conditions in megaproject construction 1st. International Conference on Infrastructure Development in Africa, p. 364

Chen, Z., Khumpaisal, S. (2009) "An analytic network process for risks assessment in commercial real estate development”, Journal of Property Investment \& Finance, Vol. 27 Iss: 3, pp.238- 258

Chen, Z.; Li H.; Hong, R.; Xu; Q.; Hong J. (2011) Total environmental risk assessment for international hub airport projects. International Journal of Project Management, 29(7) (2011) 856-866.

Chritamara S., Ogunlana S.O., Bach N.L., (2002) "System dynamics modelling of design and build construction projects", Construction Innovation: Information, Process, Management, Vol. 2 Iss: 4, pp.269- 295

De Marco A., and Rafele C. (2009), Using system dynamics to understand project performance. Available at http://www.aice-it.org/index. php/.../27-ingegneria-economica-n-79-all-2 (Accessed 21 October, 2011) 
Flyvbjerg, B. (2007), cost overruns and demand shortfalls in urban rail and other infrastructure, Transportation Planning Technology (2007) Vol. 30, No. 1, pp. 9-30

Flyvbjerg, B. (2006b) From Noble Price to project management: getting risk right. Project management journal, 37 (3), 5-15

Flyvbjerg, B., Bruzelius, N., Rothengatter W. Megaprojects and Risks: An Anatomy of Ambition, Cambridge Univ. Press, Cambridge, UK, 2003, p.86

Godfrey, P.S. (1996). Control of Risks - A guide to the systematic management of risks for construction. CIRIA Publication, Westminster, London.

Gray C. and E. Larson (2006) Project Management: The Managerial Process, 3rd Edition, McGraw-Hill.

Howick, S. (2003) Using System Dynamics to Analyse Disruption and Delay in Complex Projects for Litigation. The Journal of the Operational Research Society, Vol. 54, No. 3 (Mar., 2003), pp. 222-229

Kytle, B. and Ruggie, J.G. (2005). Corporate social responsibility as risk management: A model for multinationals. Working paper number 10

Love, P.E.D., Holt G.D, Shen L.Y., Lib H., Irani Z. (2002). "Using systems dynamics to better understand change and rework in construction project management systems". International Journal of Project Management Vol. 20, Issue: 6, (2002) Elsevier, pp. 425-436

Mawby, D. Stupples, D. (2002) Systems Thinking for Managing Projects, Engineering Management Conference 2002

Mugeni-Balyejusa B. (2006). “An application of system dynamics modelling to changes in construction projects". Available at http:// hdl.handle.net/123456789/585 (Accessed 20 September, 2011)

Nasirzadeh F.; Afshar A. and Khanzadi M. (2008) 'System dynamics approach for construction risk analysis' International Journal of Civil Engineering, Vol. 6, No. 2.

Naseena J. and Bhatt, M.S. (2006) Modelling and Simulating the Dynamics in Project Monitoring and Earned Value analysis, Journal of Advances in Management Research, Vol 3(1), pp 26-43.

Ogunlana S.O., Sukhera and Li, H., (2003). “System Dynamics Approach to Exploring Performance Enhancement in a Construction
Organization.”, J. Constr. Engrg and Mgmt. ASCE.129. pp. 528-536)

Poole, R. W. Jr. (2004) “Addressing the 'Big Dig Syndrome'”. Public Works Financing, May 14, 2004

Park, M. (2002), Dynamic Change Management for Fast-tracking Construction Projects. Available at http: //www.iaarc.org/pe_ publications.htm. (Accessed o5 October, 2011)

A. Rodrigues, Bowers J. 1996. System dynamics in project management: a comparative analysis with traditional methods. System Dynamics Review 12(2): 121-139.

Senge, P. (1990). The Fifth Discipline: The Art and Practice of The Learning Organization. New York. Doubleday

Sterman J. D (2000). Business Dynamics System thinking and modelling for complex world, Irwin McGraw-Hill

Sterman J. D (1992) Systems Dynamic Modelling for Project Management, Sloan School of Management, MIT Cambridge

Sushil (1993) System Dynamics: A Practical approach for managerial problems, Wiley Eastern Limited, New Delhi.

Sycamore, Douglas and Collofello, James S. (1999) Using System Dynamics Modelling to Manage Projects, Twenty-Third Annual International Computer Software and Applications Conference, p. 213.

Towell R. Denis (1993) System DynamicsBackground, Methodology and Applications, Computing and Control Engineering Journal, October, pp 201-208

\section{Acknowledgements}

The research is funded by the doctoral research scheme in the Institute for Building and Urban Design in the School of the Built Environment at Heriot-Watt University in Edinburgh, the United Kingdom. The study is also a part of initiatives of megaproject research project that is funded by the European Cooperation in Science and Technology (COST) through COST Action TU1003, which aims at the Effective Design and Delivery of Megaprojects in the European Union. The European Cooperation of Science Foundation provides the COST Office through a European Commission contract. The Council of European Union provides the COST Secretariat. The Action is chaired by Professor Naomi Brookes in the School of Civil Engineering at the University of Leeds, and there are participants from over 19 countries across Europe. 